\title{
A Retrospective Study on Anatomical Variants of the Uncinate Process: What the Radiologist Needs to Inform the Surgeon?
}

\section{ABSTRACT}

Introduction: Uncinate Process (UP) is a crucial component of the anterior Osteomeatal Complex (OMC), which is a key area for the drainage and ventilation of the anterior group of paranasal sinuses.

Aim: To determine the prevalence of various anatomic variants of the UP, like its varying superior attachment to vital structures like the lamina papyracea, skull base or the middle turbinate, angulation (medial or lateral), pneumatisation (uncinate bulla) and atelectatic UP using Computed Tomography (CT) images of the paranasal sinuses.

Materials and Methods: A retrospective cross-sectional study was conducted in the Radiodiagnosis department of a Tertiary care hospital from December 2019 through January 2020 , to determine the prevalence of various anatomic variants of the UP. CT scans of the paranasal sinuses of 200 patients (males 102; females 98) in the age group of $17-70$ years, were analysed in coronal view of bone window and the superior attachments of UP were classified based on the Stammberger and Hawke classification.

Results: Of the total 200 images (400 sides), type I attachment to the Lamina Papyracea (LP) was most frequent $64.5 \%$ in 258 number of cases. Least common variation was the Type II attachment to the skull base $5 \%$ in 20 cases. UP pneumatisation (uncinate bulla) was less commonly seen variation in 25 cases. Normal vertical orientation of the UP was seen in 34 cases, Only two cases each of horizontal lateral and medial angulation and in both cases findings were unilateral.

Conclusion: In order to determine the prevalence of various anatomic variation of the UP, especially its various superior attachments, the study examines the CT images of 200 patients and found that the variations in superior attachment found to be more frequent than the other variations and the commonest was the Type I, attachment to the LP directly or indirectly by attaching to the Agger Nasi Cells (ANC).

\section{INTRODUCTION}

The UP is a thin crescent-shaped bony projection that arises from the inferior turbinate ethmoidal process, extending antero-superiorly to the frontal recess, and is considered one of the lateral nasal cavity's most important landmarks $[1,2]$. It is a key component of the anterior $\mathrm{OMC}$, a key region for the drainage and ventilation of the anterior $\mathrm{OMC}$. The OMC consists of the hiatus semilunaris, a two-dimensional crescent-shaped region located between the free edge of the UP and the anterior surface of the Bulla Ethmoidalis (BE), extending laterally into the ethmoid infundibulum [3,4], a three-dimensional gutter. Both sides of the maxillary sinus ostium open into their corresponding infundibulum. UP shows recurrent and numerous anatomic variations like variations in its superior attachment, its orientation (medial or lateral angulations) and pneumatisation of its tip. Most substantial variations are those of Superior Attachment of the Uncinate Process (SAUP) to vital structures like the LP (medial orbital wall), skull base or middle turbinates. These variations have functional and surgical consequences as they regulate the draining of frontal recess either into the middle meatus or into the ethmoid infundibulum. During endoscopic sinus procedures, the superior most segments remains a blind spot for the surgeons $[5,6]$. A three-dimensional potential space is a frontal recess, a drainage channel of the frontal sinus ending inferiorly in the nasal cavity. It is lined anteriorly by the maxilla, frontal beak, ANC frontal process, laterally by the BE antero-superior wall, laterally by the LP and medially by the olfactory fossa [7]. The medial and lateral boundaries differ according to the variations in the SAUP. The superior Attachment of the uncinate process will also determine the direction of frontal sinus outflow, finally into the middle meatus and ethmoidal infundibulum, either medial or lateral to UP [8].
This region is susceptible to frequent anatomical variations, some of which may compound drainage and ventilation obstructions due to microbe inflammation or allergens resulting in chronic rhinosinusitis [8]. Uncinate and ethmoid bulla processes may have a ventilatory and protective function by preventing nonsterile air from entering and allowing only sterile expirations. In the assessment of anatomical variants of the paranasal sinuses and structures comprising the $\mathrm{OMC}, \mathrm{CT}$ is the modality of choice, thus playing an important role in directing surgical and medical treatment. In order to avoid injury to the skull base, LP and middle meatus during uncinectomy, surgical procedures to restore the normal drainage pathway therapy require preoperative knowledge of the anatomy and anatomical variations of the important structures of this region $[9,10]$. During Functional Endoscopic Sinus Surgery (FESS), preoperative details on the nature of anatomical variants direct the surgeon in order not to injure these structures intraoperatively. Uncinate is a crucial landmark during FESS and is first removed in endoscopic sinus surgery to allow visualisation of the opening of the maxillary sinus and a blind spot during endoscopy is the upper end of UP [11]. The present study is aimed to determine the prevalence of various anatomic variants of the UP, like its varying superior attachment to vital structures like the lamina papyracea, skull base or the middle turbinate, angulation (medial or lateral), pneumatisation (uncinate bulla) and atelectatic UP using CT images of the paranasal sinuses.

\section{MATERIALS AND METHODS}

This was a retrospective cross-sectional study of coronal CT images of the paranasal sinuses of 200 consecutive patients referred to the Radiodiagnosis department of a Tertiary care hospital from December 2019 through January 2020. 


\section{Inclusion criteria}

- Patients with sinonasal symptoms, who were referred from different clinical Outpatient Department (OPD) and wards to the Department of Radiodiagnosis.

- $\quad$ Patients of both sexes (male 102; female 98)

- Patients between the age group of 17-70 years.

- Patients who are willing to participate were included in the study.

\section{Exclusion criteria}

- The excluded age group was $<17$ years and $>70$ years

- Trauma to face

- Diseases invading and eroding the bones of sinuses

- Invasive, polypoidal, expansile, and neoplasms of PNS

- Patients whose OMC was altered or obscured by sinonasal surgery, trauma, tumour, chronic sinusitis or extensive sinonasal polyposis were excluded from the study.

All the images were acquired on Philips Mx multi slice scanner with same specifications, $2 \mathrm{~mm}$ slice thickness, and optimal exposure settings of $160 \mathrm{kVp}, 120 \mathrm{~mA}$, without injecting IV contrast. The reconstructed images were analysed by a 20 years experienced radiologist on Osirix MD Dicom Viewer operating system in coronal plane using bone window setting to optimally visualise the anatomy and the various anatomical variants of the UP and the results tabulated. Since it was a retrospective study, no extra radiation was imposed on patients and their personal information were undisclosed.

\section{Assessment of Anatomical variations of the Uncinate Process (UP)}

The variants were defined as per anatomic terminology group. Typical UP was taken to be a thin hook like structure with a near sagittal orientation.

Superior Attachments of Uncinate Process (SAUP): According to the Stammberger and Hawke classification (1991) [12], the attachments were classified as Type I-attachment to the LP directly or to the anterior ethmoid cell/ANC, Type II-attachment to the skull base, Type IIIattachment to the middle turbinate and Type IV- free type, with free end lying in the middle meatus. The Type I to Type IV classification types were commonly reported in the present study population.

\section{STATISTICAL ANALYSIS}

Data was statistically analysed in the form of percentages for various anatomical variations of UP.

\section{RESULTS}

A total of 200 coronal CT mages (400 sides) of the paranasal sinuses were reviewed. Among the study group, 102 were males, 98 were females, age range was between $15-70$ years and majority were in the 15-25 age group with (49\%) [Table/Fig-1]. The variations showed no predilection for any sex or any particular age group. In this study, the commonest type of uncinate variations was seen in its superior attachment. [Table/Fig-2] depicted the superior attachment of the UP and the most frequent variation identified was Type I, attachment to the LP seen in 258 (64.5\%) and the least common

\begin{tabular}{|c|c|c|}
\hline Variable & Number of cases $(n=200)$ & Percentage \\
\hline \multicolumn{3}{|l|}{ Sex } \\
\hline Male & 102 & 51 \\
\hline Female & 98 & 49 \\
\hline \multicolumn{3}{|c|}{ Age group (Years) } \\
\hline $15-25$ & 98 & 49 \\
\hline $26-36$ & 50 & 25 \\
\hline $37-47$ & 34 & 17 \\
\hline 48 and above & 18 & 9 \\
\hline
\end{tabular}

was Type II, attachment to the skull base 20 (5\%) [Table/Fig-2,3]. The other variations which were less frequent seen were, UP to pneumatisation which was seen in 25 (8\%) cases [Table/Fig-3,4]. Variation in orientation of UP, was not very frequently seen, most of the cases showed normal angulation 162 cases (81\%) followed by vertical orientation 34 (17\%) [Table/Fig-5] and only one case of atelectasis of UP was seen [Table/Fig-3,6].

\begin{tabular}{|l|c|c|c|c|}
\hline \multirow{2}{*}{ Variable } & \multicolumn{2}{|c|}{ No. of cases ( $\mathrm{n}=\mathbf{4 0 0}$ sides) } & $\begin{array}{c}\text { Number of } \\
\text { cases and } \\
\text { percentage }\end{array}$ \\
\cline { 2 - 4 } & Left & right & bilateral & $258(64.5 \%)$ \\
\hline $\begin{array}{l}\text { Type I-Lamina papyracea/Aggaer } \\
\text { nasi (ANC) }\end{array}$ & 11 & 7 & 120 & $20(5 \%)$ \\
\hline Type II-attached to the Skull base & 1 & 1 & 9 & $80(20 \%)$ \\
\hline $\begin{array}{l}\text { Type III-attached to the middle } \\
\text { turbinate }\end{array}$ & 7 & 5 & 34 & $42(10.5 \%)$ \\
\hline Type IV-free type & 8 & 4 & 15 & 40 \\
\hline
\end{tabular}

[Table/Fig-2]: Superior Attachment of the Uncinate process (SAUP).
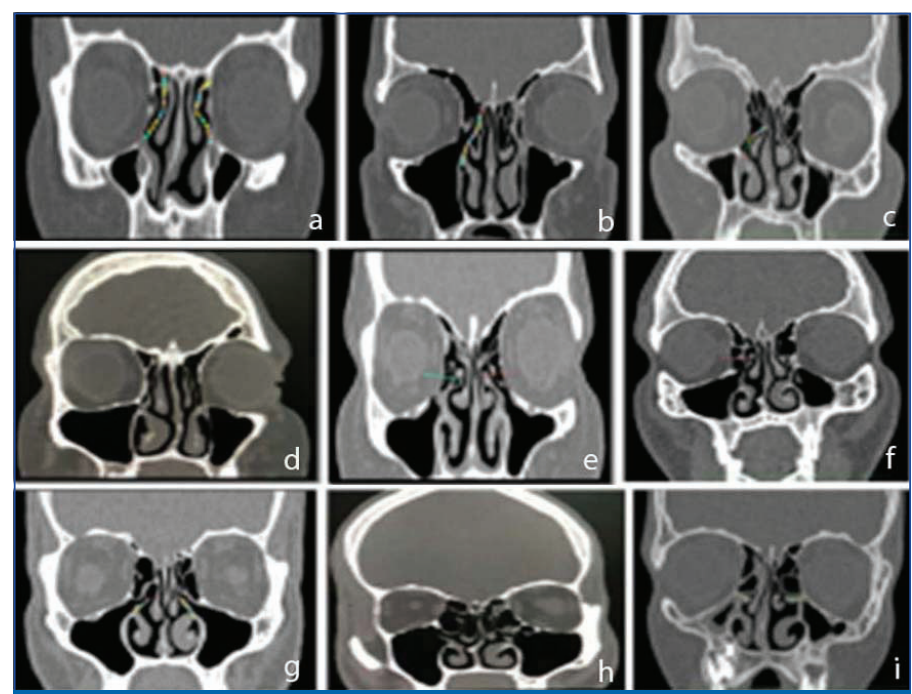

[Table/Fig-3]: a) Type I (Lamina Papyracea (LP) attachment on left ; b) Type II (Skull

base) on the right; c) Type III (middle turbinate) on the right ; d) Type III (middle turbinate attachment bilaterally; e) Uncinate Process (UP) pneumatisation bilaterally; $f$ Unilateral uncinated process pneumatisation right; g) Type IV (free), with tip in the middle meatus and normal angulation; h) Uncinate Process (UP) showing lateral horizontal angulation on right and medial horizontal angulation on the left; i) Atelectatic UP bilaterally, fused with the infero-medial orbital floor associated with bilateral hypoplastic maxillary sinus and bilateral descent of the orbital floor.

\begin{tabular}{|l|c|}
\hline Variable & Number of cases $(\mathrm{n}=25)$ and percentage \\
\hline Unilaterally pneumatised UP & $18(72 \%)$ \\
\hline Bilaterally pneumatised UP & $7(28 \%)$ \\
\hline
\end{tabular}

\begin{tabular}{|l|c|}
\hline Variable & Number of cases $(\mathrm{n}=200)$ and percentage \\
\hline Normal orientation & $162(81 \%)$ \\
\hline Vertical orientation & $34(17 \%)$ \\
\hline Horizontal orientation-Medial & $2(1 \%)$ \\
\hline Horizontal orientation-Lateral & $2(1 \%)$ \\
\hline
\end{tabular}

\begin{tabular}{|l|c|}
\hline Variable & Number of cases $(\mathrm{n}=200)$ and percentage \\
\hline Atelectatic UP Unilateral & $0(0 \%)$ \\
\hline Atelectatic UP-bilateral & $1(0.5 \%)$ \\
\hline [Table/Fig-6]: Atelectatic Uncinate Process (UP).
\end{tabular}

\section{DISCUSSION}

In recent times, rapid advances in imaging technology, especially in the imaging of the paranasal sinuses, have made it possible to study the anatomy of this region in detail and subtle anatomical variations in structures such as the turbinates in this region (paradoxical bending, pneumatisation etc.,), Haller cells, and in the 
UP (pneumatisation, orientation, SAUP etc.,) are now recognised routinely on CT scans $[13,14]$. In certain cases of chronic and refractory sinusitis and headaches, these anatomical differences can clinically play a role due to their detrimental effect on sinus ventilation and drainage by obstructing the drainage pathways, which can contribute to or intensify inflammatory conditions such as rhinosinusitis in combination with inflammation of the lining mucosa. A part of the anterior OMC (Osteo Meatal Complex), responsible for the drainage of the frontal sinus, maxillary sinuses and anterior ethmoid air cells, is the UP. It has both a practical and protective role in ventilation, enabling only sterilised expiratory air to reach the sinuses and preventing the entry into the sinuses of inspired unsterile air [15-17].

The purpose of the study was to determine the prevalence of various anatomic variation of the UP, especially its various superior attachments, which need to be identified and mentioned during the preoperative CT evaluation of the paranasal sinuses, in order to avoid intraoperative injury to important structures like the LP, skull base, and middle turbinate. In the present study, CT images of 200 patients (400 sides), were evaluated to determine the variations in superior attachment and found to be more frequent than other variations. Commonest was the Type I, attachment to the LP directly or indirectly by attaching to the ANC seen in $64.5 \%$ cases. This was almost similar to results in studies by Turget $\mathrm{S}$ et al., (63\%) and Netto B et al., (63.5\%), but it was lower than the study by Tuli IP et al., (79.8\%) and more than that reported in the study by Kumar NV et al., (55\%) [18-21]. Type III, attachment to the middle turbinates, was second most common type seen in $20 \%$ of cases. Only study by Kumar NV et al., showed similar result of $20 \%$ prevalence [21]. While all other studies by Turget S et al., (8\%), Netto B et al., (6.3\%) Tuli IP et al., (3.35\%), and Lansberg R et al., (1.4\%), showed Type II to be least common type [18-20,22]. Type IV or Free types of UP, with no superior attachment was found to be third in prevalence in present study, seen in $10 \%$ of cases. The present study result was similar to the study by Kumar NV et al., who reported it in $11 \%$ of cases and found it like us to be third most prevalent type [21]. Type II attachment to the skull base was the least common variant in the current study, seen in only $5 \%$ of cases. Studies by Netto B et al., (6.3\%) Kumar NV et al., (8\%), and Lansberg R and Friedman M, (3.6\%), showed almost similar prevalence as present study $[19,21,22]$. Other studies by Turget $S$ et al., (14\%), Tuli IP et al., (16.6\%), showed higher prevalence than present study [18,20]. But only Kumar NV et al., found in to be least common variant as in current study [21]. Rest of the studies mentioned Type II to be second most prevalent variant. The present study showed results similar to the study by Kumar NV et al., showing the prevalence of superior attachment, to be in the order of Type I, Type III, Type IV and Type II [21]; while rest of the studies by Turget $S$ et al., Netto B et al., Tuli IP et al., Lansberg R and Friedman M, Isha Preet T et al., and Uma Devi Murali AR showed the order as Type I, Type II and Type III variations [18-20,22-24]. [Table/Fig-7] showed the comparisons of present study results with the past studies [18-22,25,26].

\begin{tabular}{|l|l|c|c|c|c|}
\hline Year & \multicolumn{1}{|c|}{ Author's } & Type I & Type II & Type III & Type IV \\
\hline 2001 & $\begin{array}{l}\text { Lansberg R and Friedman } \\
\text { M, [22] }\end{array}$ & $60.5 \%$ & $3.6 \%$ & $1.4 \%$ & - \\
\hline 2005 & Turgut S et al., [18] & $63 \%$ & $14 \%$ & $8 \%$ & - \\
\hline 2013 & Tuli IP et al., [20] & $79.8 \%$ & $16.67 \%$ & $3.57 \%$ & - \\
\hline 2013 & Sagar GRS et al., [25] & $82 \%$ & $14 \%$ & $4 \%$ & - \\
\hline 2014 & Gnanavelraja C et al., [26] & $72 \%$ & $22 \%$ & $6 \%$ & - \\
\hline 2015 & Netto B et al., [19] & $63.5 \%$ & $6.3 \%$ & $6.3 \%$ & - \\
\hline 2015 & Kumar NV et al., [21] & $55 \%$ & $8 \%$ & $20 \%$ & $11 \%$ \\
\hline 2016 & Present study & $64.5 \%$ & $5 \%$ & $20 \%$ & $10.5 \%$ \\
\hline
\end{tabular}

The frontal sinus outflow was categorised by Lansberg $R$ and Friedman $M$ into two forms, based on the SAUP, i.e., medial to UP or lateral to UP. The frontal outflow is directly into the middle meatus, in the case of Type I SAUP. This is the most common form of outflow tract of the frontal sinus (72\%). In such cases, ethmoidal infundibulum ends superiorly as a recessus terminalis blind pouch. The outflow tract is lateral to UP in Type II and III and the frontal recess drains into the middle meatus through ethmoidal infundibulum (28\%) [22]. As the first phase, endoscopic sinus operations begin with an uncinectomy. A poorly performed uncinectomy may lead to the entire procedure failure and can lead to complications of orbital and lacrimal function. Therefore, it is mandatory for the operating surgeon to be aware of the usual anatomy and uncinate method variations [16].

\section{Limitation(s)}

The sample size of two hundred patients seems inadequate, based on the literature survey of past research, and there may be a bias in expanding the findings to the general population. There is always a degree of human error conceivable.

\section{CONCLUSION(S)}

In order to determine the prevalence of various anatomic variation of the UP, especially its various superior attachments, the study examines the CT images of 200 patients and found that the variations in superior attachment found to be more frequent than the other variations and the commonest was the Type I, attachment to the LP directly or indirectly by attaching to the ANC. Since CT is recognised as a gold standard method and routinely used to assess the OMC region's anatomy and pathology thus, it is absolutely essential for the evaluation of patients considered for surgery. The very high prevalence of the anatomic variants in the UP, as perceived in the present study recommends a large study in the general population, in the future to determine the relationship of the anatomical variants with various pathological conditions that commonly occur in the para nasal sinus.

\section{Acknowledgement}

The author would like to thank the entire faculty members, technicians of Radiodiagnosis department, GIMSR for their support during the study.

\section{REFERENCES}

[1] Bayram M, Sirikci A, Bayazit YA. Important anatomic variations of the sinonasa anatomy in light of endoscopic surgery: A pictorial review. Eur Radiol. 2001;11(10):1991-97.

[2] Kaluskar SK, Sachdeva S. Complications in endoscopic sinus surgery: Diagnosis, prevention and management. New Delhi: Jaypee Brothers Medical Publishers (p) Ltd. $1^{\text {st }}$ Edition. 2002.

[3] Stammberger H, Hawke M. Essentials of endoscopic sinus surgery. St. Louis: Mosby Inc. $1^{\text {st }}$ Edition. 1993:01-108.

[4] Gulay G, Nazan O, Erdogan O. Uncinate process variations and their relationship with ostiomeatal complex: A pictorial essay of Multidedector Computed Tomography (MDCT). Polish Journal of Radiology. 2016;81:173-80.

[5] Liu X, Han D, Zhou B. Relationship between anatomic variants of nasal sinus and chronic sinusitis. Zhonghua Er Bi Yan Hou Ke Za Zhi. 1998;33:149-52.

[6] Rysz M, Bakon L. Maxillary sinus anatomy variation and nasal cavity width: Structural computed tomography imaging. Folia Morphol. 2009;68:260-68.

[7] Peynegre R, Rouvier P. Anatomy and Anatomical Variations of the Paranasal Sinuses Totowa, NJ: Humana Press; 1996:03-32.

[8] Krzeski A, Tomaszewska E, Jakubczyk I, Galewicz-Zielinska A. Anatomic variations of the lateral nasal wall in the computed tomography scans of patients with chronic rhinosinusitis. Am J Rhinol. 2001;15(6):371-75.

[9] Lloyd GA. CT of the paranasal sinuses: Study of a control series in relation to endoscopic sinus surgery. J Laryngol Otol. 1990;104:477-81. Doi: 10.1017/ S0022215100112927

[10] Wani AA, Kanotra S, Lateef M, Ahmad R, Qaji SM, Ahmad S. CT scan evaluation of the anatomical variations of the osteomeatal complex. Indian J Otolaryngol Head Neck Surg. 2009;61:163-68. Doi: 10.1007/s12070-009-0059-8.

[11] Nayak DR, Balakrishnan R, Murty KD. Functional anatomy of the uncinate process and its role in endoscopic sinus surgery. Indian J Otolaryngol Head Neck Surg. 2001;53:27-31.

[12] Stammberger H, Koop W, Dekornfeld TJ. Special endoscopic anatomy. In: Stammberger H, Hawke M, editors. Functional Endoscopic Sinus Surgery: The Messerklinger Technique. Philadelphia, PA: BC Decker; 1991;61-90. 
[13] Bolger WE, Butzin CA, Parsons DS. Paranasal sinus bony anatomic variations and mucosal abnormalities: CT analysis for endoscopic sinus surgery. Laryngoscope. 1991;101:56-64

[14] Basic N, Basic V, Jukic T, Basic M, Jelic M, Hat J. Computed tomographic imaging to determine the frequency of anatomical variations in pneumatisation of the ethmoid bone. Eur Arch Otorhinolaryngol. 1999;256:69-71.

[15] Sushilkumar K, Preetha K. Evaluation of anatomical variations in ostiomeatal unit by computed tomography. International Journal of Scientific Study. 2018;5(12):56-60.

[16] Arun G, Moideen SP, Mohan M, Afroze AK, Thampy AS. Anatomical variations in superior attachment of uncinate process and localization of frontal sinus outflow tract. Int J Otorhinolaryngol Head Neck Surg. 2017;3:176-79.

[17] Elwany S, Elsaeid I, Thabet H. Endoscopic anatomy of the sphenoid sinus. J Laryngol Otol. 1999;113:122-26.

[18] Turgut S, Ercan I, Sayın I, Başak M. The relationship between frontal sinusitis and localization of the frontal sinus outflow tract: A computer-assisted anatomical and clinical study. Arch Otolaryngol Head \& Neck Surg. 2005;131(6):518-22.

[19] Netto B, Piltcher OB, Meotti CD, Lemieszek J, Isolan GR. Computed tomography imaging study of the superior attachment of the uncinate process. Rhinology. 2015;53(2):187-91.
[20] Tuli IP, Sengupta S, Munjal S, Kesari SP, Chakraborty S. Anatomical variations of uncinate process observed in chronic sinusitis. Indian J Otolaryngol Head Neck Surg. 2013;65(2):157-61.

[21] Kumar NV, Kamala E, Priya TG, Nalinakumari SD. A computerized tomographic study of uncinate process of ethmoid bone. Int $\mathrm{J}$ Anat Res. 2015;3(1):917-21.

[22] Lansberg R, Friedman M. A computer-assisted anatomical study of the nasofrontal region. Laryngoscope. 2001;111:2125-30.

[23] Isha Preet T, Subhabrata S, Suvamoy C. Anatomical variations of uncinate process observed in chronic sinusitis. Indian J Otolaryngol Head Neck Surg. 2013;65(2):157-61.

[24] Uma Devi Murali AR, Dev B. Pictorial essay: Anatomical variations of paranasal sinuses on multidetector computed tomography-How does it help FESS surgeons? Indian Journal of Radiology and Imaging. 2012;22(4):317-24.

[25] Sagar GRS, Bhal Chandra JHA, Meghanadh. A study of anatomy of frontal recess in patients suffering from 'chronic frontal sinus disease'. Indian J Otolaryngol Head Neck Surg. 2013;65(Suppl2):S435-39.

[26] Gnanavelraja C, Senthilnathan V, Vijayakumar M, Ramesh M, Rajajeyakumar M, Subramanian TK, et al. Anatomical variations in the superior attachment of uncinated process and its association with frontal sinusitis. MIMJ. 2014;1(8):399-401.

\section{PARTICULARS OF CONTRIBUTORS:}

1. Associate Professor, Department of Radiodiagnosis, GITAM Institute of Medical Sciences and Researh, GITAM, Deemed to be University, Visakhapatnam, Andhra Pradesh, India.

NAME, ADDRESS, E-MAIL ID OF THE CORRESPONDING AUTHOR:

\section{Dr. Sonica Sharma,}

Associate Professor, Department of Radiodiagnosis, GITAM, Deemed to be University,

Rushikonda, Visakhapatnam, Andhra Pradesh, India.

E-mail: jyothipgis@gmail.com; sonicasharma10@gmail.com

\section{AUTHOR DECLARATION}

- Financial or Other Competing Interests: None

- Was Ethics Committee Approval obtained for this study? NA

- Was informed consent obtained from the subjects involved in the study? NA

- For any images presented appropriate consent has been obtained from the subjects. NA
PLAGIARISM CHECKING METHODS: Jain Het al.]

- Plagiarism X-checker: Sep 16, 2020

- Manual Googling: Dec 03, 2020

- iThenticate Software: Mar 03, 2021 (11\%)
ETYMOLOGY: Author Origin

Date of Submission: Sep 14, 2020 Date of Peer Review: Dec 13, 2020

Date of Acceptance: Jan 17, 2021 Date of Publishing: Apr 01, 2021 